\title{
From the Chair of the Presidency
}

\begin{abstract}
Libraries must exploit various new technologies to control the information explosion. In spite of past failures and resistance by librarians to the use of the new technology, lessons have been learned on how it can be employed successfully. Greatest immediate impact is seen in the use of the computer, miniaturization, broad band communication, video reproducers, and graphic devices.
\end{abstract}

$\mathbf{I}$ N THEIR CONSIDERATION OF LIBRARIES, there are several areas in which most college presidents agree: (1) it requires time and money to improve services; (2) an answer must be found to the cost and physical expense of library buildings; (3) the retrieval efficiency of the conventional library must be improved; (4) the inflationary cost rises presently reflected within the library must not bear a growth ratio within the total cost of college operations greater than the rising cost of other essential services within the institution; and (5) it is quite possible for a college president to take the view that the library of his institution has become too important to be left to the librarians alone.

An explanation of the last remark lies in the changing nature of our institutions and their administration. A major emphasis for many institutions is a deep concern for maintenance of enrollment. The competition among public and private sister institutions for the "traditional" entering freshman

Alexander Schure is president, New York Institute of Technology, Old Westbury. This article is based on an address delivered at the ACRL College Libraries Section program meeting, "The Task of College Libraries in the Seventies," in New York, July 1974. grows fiercer. The declining birth rate seems to indicate that this source for most schools will shrink, at least in the immediate future. The one trend which heartens most administrators is the growing emphasis in continuing education. It has produced a new college market for adults and a series of alternatives to traditional education. The thrust of both of these directions is to turn much of education and many of the students away from the local central campus. The information contained in the college campus library must eventually be able to reach these students easily. This requires techniques and technologies more sophisticated than those available in most libraries.

\section{INFORMATION AND LIBRARIES}

Modern campuses mirror the transitions occurring everywhere. A host of social, economic, scientific, and technological factors are remolding our society and, along with it, the nature of modern education. Dr. Andrew R. Molnar of the National Science Foundation, describing the information explosion the world is undergoing, notes " 90 percent of all the scholars who have ever contributed to the body of scientific knowledge are alive today." $\mathrm{He}$ adds:

Information is increasing exponential- 
ly and can be expected to double in the next twelve years. If a given discipline or specialization could be assumed to contain one one-thousandth of all knowledge, and if a scientist were to read at the rate of 3,000 characters per minute (about the rate at which we read a novel), and if he were to read thirteen hours a day for 365 days per year, it would take him twelve years to read everything in his specialty. At the end of this time, he would find that he was twelve years behind in his reading and that the volume of new materials had doubled. Sixty years ago, a scientist would be required to read twenty-five minutes per day. Twelve years from now he will have to read continuously, day and night, every day of the year. ${ }^{1}$

A statement from the National Advisory Commission on Libraries gives an apt summary on the condition of libraries-what is now and what probably will be:

The purpose and general character of library services have not changed greatly over the past forty years. What have changed for most libraries are the range and volume of demand and use. The rapid and pervasive growth of specialization in new subject matters, together with an increasingly large and literate user population, has placed severe burdens on libraries of all kinds. .... If the libraries are to do more than keep pace-i.e., to provide better and broader service than they now do-a much more aggressive and integrated approach to improvement will be needed. . . . It will be necessary to think in terms of more interdependent modes of operation. It will also be necessary to take better advantage of the developing technology. ${ }^{2}$

In his 1945 article in Atlantic Monthly, Dr. Vannevar Bush wrote:

The summation of human experience is being expanded at a prodigious rate, and the means we use for threading through the consequent maze to the momentarily important item is the same as was used in the days of the square-rigged ships. ${ }^{3}$

Since that statement the expanded range of available communication technology can be demonstrated by even a partial listing of communication (and library applicable) technologies, including: (1) multiplex radio, high speed facsimile, laser, satellite transmission, microwaves; (2) LP disc and paper records, video and audio recorders, discs and playbacks; (3) television, color television, interactive cable television, cassette television; and (4) computers and data processing, minicomputers and miniperipherals.

We come then, not surprisingly, to the application of technology as it relates to the library, a process still in its infancy. Relatively few libraries really use the sophisticated technologies in any major fashion. This is both understandable and not too disturbing. Just as it has taken the aerospace industry from 1903 to 1973 to move from Kitty Hawk to a probe of Mars, it is likely we shall see (in some shorter span than that seventy years) library technology having the impact and capabilities that its most enthusiastic proponents advocate for it. At this moment, though, the technologies we have on-line in most library facilities, while varied, are basically primitive.

\section{The College President and TeChNOLOGY}

Administrators see their library facilities in terms of their actual capacity to serve the constituency of their institutions; and from this vantage point they proceed to assess priorities with respect to the economics of the library operation. In critical budget times, answers to the urgent fiscal problems confronting administrators and trustees are not likely to come from the presently available hardware and systems conveniently described as "library technology." In the present state of the art it is prema- 
ture to anticipate technology as the means of reducing the relentlessly rising costs of library services. Yet increasing potentials for relief by way of technology are on the horizon. To quote James Koerner of the Sloan Foundation, "History suggests that new technologies are often overrated in the short run but vindicate their prophets in the long run."4

College presidents have obvious concerns as they ponder decisions to be made with respect to their recommendations for funding library projects relating to technology. They have learned painful lessons with similar causes. The failures of the past, easily identifiable, are quite parallel to the rationale for lack of success to date with educational technology and are worth recapitulating:

1. The equipment or hardware used has often fallen short of claims made for it. The more complex and advanced the hardware systems, the more serious the problems of reliability, maintenance, and incompatibility with other systems.

2. Institution-wide standardization is not present. Further, the obsolescence rate of hardware is substantial, requiring capital investment for new or improved systems continuously. Then the programming or software has not kept pace with hardware development.

3. Not enough fundamental research has been carried out to identify with precision the direct nature and needs of library and information researchers. It is necessary for us to know more about the fashion in which information utilization takes place with heterogeneous groups of library users.

4. Past failures reflect a number of additional factors. Projects are often begun without definitive articu- lation of purpose; without prior attention to the technical components of the project; without direct involvement of the participants, particularly librarians; without thorough orderly evaluation; or without adequate understanding of the attitudes of librarians toward the whole concept of technology within the library.

\section{Librarians and TechNology}

Since administrators interact with librarians, it is helpful to suggest rationales as to why working librarians tend to resist technology:

1. The basic conservatism of the library establishment.

2. Fear of the effects of library technology on the professional librarian's role and responsibilities.

3. The ineptitude and insensitivity of the equipment manufacturers.

4. The insensitivity and ineptitude of administrators.

5. A minimal or nonexistent involvement of professional librarians at the various steps of the process of introduction of technology.

Another major cause for resistance of the librarian lies in the apprehension engendered by an increasingly sophisticated library technology. Librarians are hesitant to acquire new responsibilities which they may not be professionally equipped to handle. They fear that technology may be library replacers instead of library extenders. They are concerned that they may lose what they regard as "the essence of professional being"; and that they will face competition from an inhuman, unpaid adversary. Technology within the library brings to many librarians a vision of invasion of their authority, a loss of autonomy, degradation of their professional privacy, and an ultimate separation from the library user. Their inter- 
pretations are those consistent with views of a downgraded position, with loss of prestige, autonomy, recognitions, and rewards.

\section{A Role for Library Technology}

The converse of the reasons we learn from our failures are guides to a formula for success in library technology applications. Thus, as essentials we can state:

1. A recognized and generally agreed upon need must exist.

2. Objectives to be achieved must be stipulated and must guide the projects.

3. An organizational structure must exist which makes success possible, or at least does not in advance assure failure.

4. Leadership must be exerted at the right level of authority, responsibility, and control.

5. Librarians must participate in their support of the project.

6. Rationality and available economics must determine the use of the techniques selected.

In 1966 a new view of libraries and information centers was presented at Princeton University. It was suggested that it may be useful to set aside the concept of a library as a collection of books and instead think of it as one part of the business of information transfer, as one segment of the conveyor belt which moves the product of intellectual activity, whether a poem or the specifications for a housing project, from the mind of the creator to the mind of the receiver.

Within the framework of the constraints already referred to, some administrators really believe that this decade will bring substantive advances within domains of technology applied to libraries. The systems most likely to have the greatest impact are:

\section{Computers}

The great strength within this technology lies in its capabilities to process vast amounts of information. Increased availability of large-scale time-sharing and dedicated minicomputers may make available greater ranges of access to information.

\section{Miniaturization}

Microfiche technology now allows substantial amounts of information to be placed on transparent material. It can then be used either through enlargement on a reading machine or reproduction onto paper. Other microforms are now used increasingly. It seems logical to expect even larger microform collections. The introduction of direct information transfer between computers and various microforms and of increasingly sophisticated ultramicroform technology is not too far in the future. It seems logical that, as costs of microfilm continue to decrease and quality to increase, electronic access to such microforms will come into increased popularity.

\section{Broad Band Communication}

These are systems capable of transferring very large numbers of visual or audio electronic signals to allow any kind of educational transmissions to audiences at almost any distance. Coaxial cables, microwave, satellites, and lasers give a capability to structure large numbers of telecommunications networks with almost unlimited capability. These networks can bind public and private institutions together to send information directly into homes or offices.

\section{Video Reproducers}

The capacity to store in compact form motion pictures on tape decks or on films for replay at the convenience of the user, when coupled with broad band technology, offers promise of com- 
bining video and computer technology. We can, through this combination, send to new audiences any amount of informal programming with illustrations and sound. Further, videotapes do not even require a transmission system. They need only access to a playback device.

\section{Books and Graphic Devices}

The availability of inexpensive copying machines and the breakthroughs in graphic techniques are reflected in the use of one of the earliest major visual arts, the book. Similarly, in the development of photocomposition the computer may well provide the libraries with several options not feasible in the past.

\section{ConCLUSION}

It is important to differentiate between trends and the most likely reality. In the next five years, from my viewpoint, printed materials will remain as the primary carriers. Professional librarians will continue to be the major catalogers and handlers of information stored within libraries, although they will be aided in many instances by the systems just described. Use of all of the sophisticated technological systems will undoubtedly increase. Administrators must be wary, however, that their priorities are the correct ones and that they help allocate to the librarians continued funds to be spent for the art of the technologically possible.

\section{REFERENCES}

1. Andrew R. Molnar, "Education and the Knowledge Society" (Washington, D.C.: National Science Foundation, 1972), p.1.

2. Douglas M. Knight and E. Shepley Nourse, eds., Libraries at Large (New York: Bowker, 1969), p.283.

3. Vannevar Bush, "As We May Think," reprinted in his Endless Horizons (Washington, D.C.: Public Affairs Press, 1946), p.1718.

4. James Koerner, "Educational Technology: Does It Have a Place in the Classroom?" Saturday Review of Education 1:46 (May 1973). 